\title{
The Motivational Structure of Appreciation
}

\author{
Servaas van der Berg
}

(This is the penultimate draft. Please cite the published version-published in Philosophical Quarterly and available here: https://doi.org/10.1093/pq/pqz004)

\begin{abstract}
On a widely held view in aesthetics, appreciation requires disinterested attention. George Dickie famously criticized a version of this view championed by the aesthetic attitude theorists. I revisit his criticisms and extract an overlooked challenge for accounts that seek to characterize appreciative engagement in terms of distinctive motivation: at minimum, the motivational profile such accounts propose must make a difference to how appreciative episodes unfold over time. I then develop a proposal to meet this challenge by drawing an analogy between how attention is guided in appreciation and how practical action is guided in 'striving play' - a mode of game play recently foregrounded in the philosophy of games. On the resulting account appreciation involves an 'inverted' motivational structure: the appreciating agent's attention is guided by cognitive goals taken up instrumentally, for the sake of the cognitive activity that results from attending under the guidance of those goals.
\end{abstract}

Keywords: aesthetic attitude, disinterest, attention, goal-directed thought, game play

\section{INTRODUCTION}

According to a contemporary version of the disinterest thesis in aesthetics, appreciation requires disinterested or non-instrumentally motivated attention. That is, to engage with an item appreciatively, one must attend to it 'without ulterior purpose', 'for its own sake', or 'for the sake of the very experience of attending to it' (see for example Stolnitz 1960; Iseminger 2005; Stecker 2006; Levinson 2016).

The thought that disinterest qualifies a way of attending instead of, as Kant (1790/2000) had it, a type of pleasure or judgment, originated with the aesthetic attitude theorists. Schopenhauer (1819/2010: 231) provides an early articulation when he locates the value of 
the aesthetic attitude in how it 'lifts us out of the endless stream of willing, tearing cognition from its slavery to the will', such that 'attention is no longer directed to the motives of willing.' The later aesthetic attitude theorists took up this thread. For Bullough (1912: 89), for example, aesthetic appreciation involves 'putting the phenomenon, so to speak, out of gear with our practical, actual self' and 'allowing it to stand outside the context of our personal needs and ends'. For Stolnitz (1960: 32-36), the aesthetic attitude requires both disinterest, which he understood to mean a lack of any motive other than just to attend, and what he called 'sympathy', which entails not imposing one's own preconceptions on the object of attention.

Aesthetic attitude theory's heyday around the mid-twentieth century was short lived, however, and many now credit George Dickie's (1964) paper, 'The Myth of the Aesthetic Attitude', with sounding its death knell. But despite Dickie's role in curtailing the attitude theorists' influence, his attack on the very existence of a disinterested mode of attention has failed to engender consensus. A chorus of dissenting voices, several of them recent (Lind 1980; Zangwill 1992; Kemp 1999; Shelley 2017; Levinson 2016: 28-31; Nanay 2016: 20_ 21; Matthen 2017, 2018), has helped the notion of an appreciative mode of attention, marked by its own peculiar motivational profile, to outlive its theoretical beginnings.

Dickie's critics are right to point out that his attack on the existence of a disinterested mode of attention was inconclusive. But pointing this out falls short of meeting the challenge his arguments pose. In particular, there is still no informative positive analysis in the literature of what 'attending for its own sake' amounts to, capable of bearing the explanatory weight routinely thrust upon the notion. The current paper takes up this challenge. It does so by revisiting Dickie's arguments and extracting from them an overlooked desideratum for accounts that seek to understand appreciation in terms of a distinctive motivational profile. 
Once this desideratum is clearly articulated (in section II), the aim will be to develop a model of appreciative motivation that meets it (sections III-V).

Two caveats are in order at the outset. What follows should not be construed as an attempt at a complete theory of appreciation, and even less so a theory of aesthetic appreciation. For a start, even if we were to grant the attitude theorists that a non-instrumental mode of attention is necessary for engaging in appreciation, this does not yet imply that it would be sufficient. Hence, the account will provide a model only of the appreciative mode of attention as put forward by the aesthetic attitude theorists. There will at most be some hints and suggestions about how the mental kind picked out by the account should feature in a complete picture of the grab bag of phenomena that sometimes go under the label of appreciation. Implicit in the background is the assumption that this mental kind is indeed central to such a picture, but the task of providing the full picture is beyond this paper's remit. ${ }^{1}$

Second, even if we find, contra Dickie, that something in the vicinity of a noninstrumental mode of attention is a real and commonplace mental phenomenon, why think that its occurrence would track the aesthetic domain? Attending to an item noninstrumentally, whatever we take that to entail, plausibly (or even likely) comes apart from ascribing aesthetic value to the item, and from attending to all or any of its aesthetic features. In other words, Dickie was right that we should not assume, as the aesthetic attitude theorists arguably did, that an account of the appreciative mode of attention could furnish an easy answer to the question of how the domain of the aesthetic is to be demarcated from other domains. For this reason the account developed below intentionally leaves open - indeed, it invites the conclusion - that there is a double dissociation between the appreciative mode of

${ }^{1}$ There is of course also a rich history of positive accounts of appreciation that do not invoke a distinctive non-instrumental mode of attention at all. These are not targets of this paper's arguments. 
attention on the one hand, and aesthetic cognition on the other. We can engage appreciatively with non-aesthetic features of the world, and we can experientially register aesthetic values and properties without thereby realizing the motivational profile underlying the appreciative mode of attention.

Despite these caveats, and notwithstanding appearances to the contrary, this paper's aims retain a deep continuity with the aesthetic attitude theorists' views. Broadly speaking, they believed that there is a distinctive mode or manner of attending that is pivotal to our aesthetic lives, that this mode supervenes on how our attention is motivated, and that it is possible to give a general account of the motivation that grounds it. What follows agrees with these commitments (at least thus formulated).

But where the attitude theorists construed appreciative attention in terms of a subject's ascription of final (that is, non-instrumental) value to the object of their attention, or to their own attentional engagement with it, the proposal below will be that no such final valuing is required. Instead, the sense in which appreciative attention is non-instrumentally motivated resides in how the appreciating subject selects cognitive goals not merely for the sake of the broader ends those goals' attainment serves, but rather for the sake of ends served by the process of being engaged in the cognitive activity that results from those goals' pursuit. Unlike in everyday cognition, the motivational relationship of means to ends is inverted in the appreciating subject's cognitive engagement with the world.

This proposal will be thoroughly unpacked below, but the argument starts with Dickie's challenge to the attitude theorists. 


\section{DICKIE'S CHALLENGE}

Crucial to the aesthetic attitude theorists' project is the feasibility of distinguishing in a principled way between disinterested (or non-instrumental) and interested (or instrumental) modes of attention. The gist of Dickie's complaint is that they conflate this distinction, between different species of attention, with a distinction between different kinds of motives for which one may attend.

Take one of Dickie's examples: Smith and Jones both listen to a piece of music, Jones with the aim of remembering its details for an exam the next day, and Smith with no such ulterior purpose. The thought is that, on the aesthetic attitude theorists' criterion, Jones's practical interest in the exam would get in the way of his simply savouring the music. Smith, on the other hand, can listen unencumbered and, provided he attends closely, his attention can rise to the level of aesthetic appreciation. Of this example Dickie (1964: 58) writes that 'what initially appears to be a perceptual distinction-listening in a certain way (interestedly or disinterestedly) - turns out to be a motivational or intentional distinction-listening for or with a certain purpose.' Disparate motives for attending, he argues, are not sufficient for disparate modes of attention: 'There is only one way to listen to (to attend to) music, although

the listening may be more or less attentive and there may be a variety of motives, intentions, and reasons for doing so' (ibid.).

Dickie's argument for this conclusion consists of a series of intuition pumps, each involving a subject whose attention would, like that of Jones, putatively count as interested on the attitude theorists' criterion. In each case, Dickie proclaims, there is either no difference between the subject's attention and that of a disinterested subject at all, or, if there is a difference, it is in what they are attending to rather than the manner of their attention. The impresario at the theatre taking pleasure in the size of the audience, for example, is not 
attending to the play interestedly, but is attending to the till instead (ibid.: 58-9). The reader approaching a poem solely for diagnostic evidence of the author's neuroses, is at worst a case of attention to the author instead of the poem, and at best, a case of partial attention to the poem (ibid.: 60). Thus, the argument goes, the distinction the attitude theorists are tracking, in so far as they are tracking any distinction at all, is not one between disinterested and interested modes of attention, but rather one between attention and distraction.

Whether we buy this line of argument depends on whether we share Dickie's intuitions in the pertinent cases, about who is attending to what, and how. The problem is that questions about who is attending to what are not always straightforward. In work on the nature of attention, Mole (2011) makes this point by emphasizing that questions about an agent's attention are connected to questions about which perceptual, cognitive, and practical tasks they are engaged in. In laboratory conditions, honing in on which task a group of experimental subjects is engaged in is a matter of experimental design. But the same precision is not available in thought experiments involving agents in ordinary circumstances:

Outside of the lab an agent's tasks will tend to be more numerous, complex, nested, and overlapping. As a result the question 'What task is this agent performing?', when asked outside the lab, may admit of many answers, some of which are only vaguely true. [...] [A]nswers to the question 'To what is this agent attending?' will inherit some of this vagueness. (Mole 2011: 52)

In as much as Dickie's arguments depend, then, on clear verdicts about what the subjects in his cases are attending to, there is room for disagreement. And if vagueness besets our intuitions concerning what an agent in ordinary circumstances is attending to, we at least 
need an argument for thinking that our intuitions about whether two agents are attending in the same way are any more probative. Dickie's critics have not been remiss in pointing this out. About the Smith and Jones example, Shelley (2017) writes:

The contention that Jones and Smith are attending in the same way appears to be question-begging, as it evidently depends on a principle of individuation that the attitude theorist rejects: if Jones's attention is governed by some ulterior purpose and Smith's is not, and we individuate attention according to the purpose that governs it, their attention is not the same.

To accept Dickie's argument, in other words, we must first accept his contention that the mode of attention exemplified in an attentional episode is not determined by the purpose that motivates the attending in that episode. But this is precisely what is under contention in his dispute with the attitude theorists. Besides his discussion of the sample of cases, Dickie offers no argument for his restrictive standard for differentiating between attentional episodes.

What arguments could he offer? To answer this question, we need an account of the relation between an attentional episode, and the purpose that motivates it. We can understand this relation in one of two ways, each corresponding to a major conception of how purposeful behaviours in general relate to their goals. Davidson (1963) famously holds that what distinguishes purposeful behaviours (actions) from mere bodily movements is that they are caused in the right way by their agents' beliefs and desires. Frankfurt (1978) criticizes Davidson's belief-desire account of action. On the alternative he proposes, calling a behaviour purposeful entails nothing about how it is initiated or caused, but rather that it is guided or kept on track by its purpose as it unfolds. 
Much has been written on this dispute in action theory and, in retrospect, it seems clear that one could make a Davidsonian account of action compatible with Frankfurt's by incorporating a more sophisticated notion of causation than the one Frankfurt's criticisms assume (see Setiya 2003: 348, n.11). But the point here is not to take sides or resolve the dispute; it is to highlight the difference in emphasis between the two views-one on causation, the other on guidance. We can use the contrast between the two views to articulate two different ways an attentional episode could relate to its goal or purpose. On a Davidsonian picture, to attend for a particular purpose would be for one's attending to have been caused by the appropriate beliefs and desires regarding that purpose. On a Frankfurtian picture, it would be for one's attention to be guided by that purpose as it unfolds. ${ }^{2}$

Return now to Dickie's standard for individuating modes of attention. His insistence that they are not differentiated by the purposes that motivate an attentional episode makes perfect sense on the Davidsonian picture. If motivation concerns just how an attentional episode is initiated or caused (in the sense of a triggering cause), then one episode can be intrinsically identical - that is, identical in contents to which the subject attends - to another episode with very different motivation (read: causal antecedents). For two differently motivated episodes to differ in mode, we need to understand their motivation on the Frankfurtian picture instead, in terms of what guides the course of an episode as it unfolds. If motivation is a matter of guidance, then a difference in type of motivation can yield a difference in the mode of attention an episode instantiates.

Just as an instance of purposeful physical behaviour may be identical in all its intrinsic properties to a set of mere bodily movements not guided by the agent, so two attentional episodes may in principle be identical in all of their contents while only one has the contents

2 The idea of applying a Frankfurtian notion of guidance to episodes of attention to capture common sense distinctions between mental kinds is due to Irving (2016: 563-4), who uses it in an account of the nature of mind-wandering. 
it does because of the right kind of guidance. As in the former case, of purposeful behaviour versus mere bodily movement, we surely want to maintain the distinction between types of attentional episodes that are differently guided. Thus the notion of a distinctive way of attending, corresponding to a distinctive motivation-or, more specifically, a distinctive kind of attentional guidance-remains a live possibility despite Dickie's insistence to the contrary.

None of this is to say that Dickie's arguments are inconsequential. In fact, once understood in this way, they pose a challenge to any feasible analysis of the appreciative motivational profile. They show that such an analysis will have to specify the distinctive motivation of appreciative episodes in the Frankfurtian guidance sense. It will not do to specify a characteristic type of reason for which appreciators attend to the object of appreciation. Rather, what is required is a characteristic type of purpose by which, or manner in which, attention to an object is guided as appreciative episodes unfold over time. Appreciative motivation, if there is such a thing, should help explain why appreciative episodes proceed as they do, rather than merely why they are engaged in at all. Until now Dickie's critics have failed to recognizes this challenge, let alone attempted to meet it. ${ }^{3}$

One reason the challenge has some real traction is that while the standard characterizations of appreciative motivation - using locutions like attending 'disinterestedly', 'non-instrumentally', or 'without ulterior purpose'-admit of quite natural Davidsonian readings, they do not admit of equally obvious Frankfurtian readings. This is in part because they are contrastive rather than positive, prohibiting certain kinds of motivations or purposes

3 A possible exception is Matthen $(2017,2018)$, whose account of appreciative (or aesthetic) motivation does imply a link between an attentional episode's motivation and how it unfolds. There is much to like about Matthen's account, but the account developed in this paper differs from his in several respects: it gives a non-hedonic reading of appreciative motivation; it shifts the focus to guidance implemented by deliberate attentional constraints (see section V); and, unlike Matthen's view, it does not tie appreciative motivation to fluent cognitive processing (Matthen 2018: 24). 
(interested, instrumental, and ulterior ones). ${ }^{4}$ But a Frankfurtian account of the motivational profile these locutions pick out should specify how attention is guided, and settling on which goals or purposes it may not be guided by, does not yet much constrain how attention must be guided to count as appreciative.

The challenge, then, is to give a positive account of appreciative motivation which could help explain why cognition unfolds as it does in appreciation. The rest of this paper develops such an account via an analogy with a practical activity we often do engage in 'for its own sake': playing games. The next section introduces the notion of 'striving play', a special form of game play that has been the focus of recent work in the philosophy of games (section III). Looking further ahead, the plan will be to show that striving play amounts to a genuinely distinctive practical mode of engaging in games (section IV) and then to argue that striving play's practical motivational structure is isomorphic to the cognitive motivational structure by which attention is guided in episodes of appreciative engagement (section V).

\section{STRIVING PLAY}

In what is by now a classic work in the philosophy of games, Bernard Suits (1978: 55) defines game play as 'the voluntary attempt to overcome unnecessary obstacles'. The point of our efforts in playing a game is not just to achieve the goal the game prescribes, but to achieve it under prescribed limitations. Suits expresses the thought in terms of a distinction between a game's lusory and prelusory goals (ibid.: 36-7). The in-game (lusory) goal of a bicycle race is not just to reach the finishing line first (the prelusory goal), but to reach it using only the permitted means (in this case, cycling along a prescribed route). Note that the

${ }^{4}$ Note that the formulation 'attending for its own sake' is also naturally read contrastively: as ruling out cases of attending for something else's sake. That is, to attend for its own sake is to attend because one attributes final (rather than instrumental) value to doing so. 
prelusory goal can be specified independently of the game's existence, but the lusory goal owes its existence to the game as constituted by the combination of the prelusory goal and the pertinent restrictions on means. On Suits's definition, all games have this structure, of pursuit of a lusory goal that is constituted by the combination of a prelusory goal and rules restricting efficient means.

One may doubt the definition's extensional adequacy, but the model of game play Suits develops in the process of defending it generates illuminating descriptions of many gamerelated phenomena. In recent work inspired by Suits, Nguyen (forthcoming: ch. 1) takes advantage of this fact by suggesting that the set of games that satisfy Suits's definition-call them 'Suitsian games' - can be approached as an independently interesting topic of inquiry, whether or not it coincides with the set that ordinary usage categorizes under 'games'. For Nguyen (ibid.), the 'most interesting possibility raised by the Suitsian analysis' is the form of engagement in Suitsian games he calls striving play.

\section{III.1. Two distinctions in game play}

To distinguish striving play from other forms of play, consider the diversity of reasons for which one might engage in a Suitsian game. Sometimes we play sudoku just for the sake of distracting ourselves on the morning commute. Wagering games and professional sports show that often money and social prestige figure into players' reasons for playing a game. We might play a sport for the sake of our physical health. Or perhaps the feeling of winning is all the reward we need. In fact, we can be maximally pluralist about potential reasons for engaging in games. Taking up a game's prelusory goal (the game-independent state to be achieved) and constitutive rules (the restrictions on means) is done for the same proximal 
reason across all cases: to make possible the activity of playing the game. But, as constituted, a game's (in-game) lusory goal can be pursued for any number of reasons.

Nguyen (ibid.: ch. 3) argues that these reasons vary along two dimensions. Firstly he distinguishes between extrinsic and intrinsic play, a distinction pertaining to whether a player ultimately engages in the game for goods internal or external to it. Secondly, both intrinsic and extrinsic players may differ with regard to the locus within game play to which the values they pursue, adhere. Nguyen dubs this the distinction between achievement and striving play: a player may care either for goods associated with the achieving of the game's lusory goal (winning) or for goods associated with the activity or process of attempting to achieve it. The two distinctions crosscut, yielding four types of play.

Intrinsic achievement players care non-instrumentally for winning; they are pure competitors. Extrinsic achievement players care for the instrumental benefits of winning, like money or social prestige. Extrinsic striving players care for game-independent benefits that result from being engaged in the in-game activity, such as the fitness or health that result from playing sport, cognitive skills acquired by playing chess, or the distraction to be had by working at the crossword. Finally, intrinsic striving players care non-instrumentally for engagement in the in-game activity. 5

Now consider how Nguyen's two motivational distinctions may be used to give two different readings of what it means to play a game for its own sake. On one reading, to play a game for its own sake is to engage in intrinsic play: to play for the sake of goods internal to the game. The distinction between extrinsic and intrinsic play presupposes a working conception of what it means to participate in a game for non-instrumental reasons. Elsewhere in value theory this kind of non-instrumental motivation is couched in the terminology of

\footnotetext{
${ }^{5}$ Nguyen (ibid.) rightly notes that these categories are not exclusive. In real world cases our reasons for engaging in games are typically mixed.
} 
final value (Korsgaard 1983; Kagan 1998). Intrinsic players ascribe final value to the game, whereas extrinsic players value it instrumentally. As final value is typically equated with value something has 'for its own sake', this makes it natural to understand intrinsic play as the paradigm case of game play for its own sake.

But notice that whether we are intrinsic or extrinsic players of a game-whether or not we attribute final value to it-is a matter of our motives for playing the game at all. The distinction pertains to why we take up the prelusory goal and rules of the game voluntarily, to whether we do so in pursuit of goods internal or external to the game we thereby constitute. Thus, the explanatory purchase that the distinction between intrinsic and extrinsic play gives us is limited to our actions with respect to the game, as opposed to our actions within the game. It answers questions such as why we play this game rather than that one, or why we spend as much time on a certain game as we do, but not questions about why our in-game pursuit of the lusory goal proceeds as it does.

What the discussion of Dickie's challenge in the last section showed is that an account of appreciative motivation should provide explanatory purchase not just on why appreciative episodes are initiated (how they are caused), but on why they unfold as they do. We want an account of appreciative motivation in the Frankfurtian sense. But an analogy with intrinsic play would be ill suited to delivering such explanation. The notion of intrinsic play gives us only a causal, Davidsonian account of play for its own sake - it explains why we play rather than why our playing goes as it does. This paper's central hypothesis is that the sense in which appreciative attention is non-instrumentally motivated is better captured by an analogy with striving play than intrinsic play. Ascribing final value to an episode of cognitive engagement (in the way the intrinsic player ascribes final value to the game) turns out to be neither necessary nor sufficient for realizing the appreciative motivational profile. 


\section{III.2. Striving play as play for its own sake}

Part of what makes striving play interesting is that it demands a kind of reversal of our ordinary means-ends engagement in practical life. Nguyen (forthcoming) calls this a 'motivational inversion', but the motivational structure underlying striving play is perhaps equally well understood as a feedback loop.

Suitsian game play in general (including both striving and achievement play) already involves a kind of inversion of means and ends. To constitute a game, one must take up the prelusory goal as an instrument. In a bicycle race, being at the finishing line is worth pursuing only in as much as pursuing it helps to bring about the game. If being at the finishing line (the prelusory goal) were too highly valued independently of the race (the restricted pursuit of the prelusory goal), then we would take the shortcut by taxi instead of cycling the long way around. The prelusory goal is thus, paradoxically, an 'end' that a Suitsian game player takes up as a means to constituting the game.

But not all participation in Suitsian games is striving play. The achievement player's reasons for taking up the prelusory goal (and thereby constituting the game) involve the potential benefits of winning, whereas the striving player's reasons involve benefits that accrue from being engaged in the in-game activity, independently of success within the game. This does not mean that she can be entirely indifferent to winning, because the activity she cares to be engaged in just is the sincere pursuit of the game's lusory goal. Like the achievement player, she must be submerged in the game to the extent that the lusory goal takes on motivational salience prompting real attempts to achieve it (more on this 'submersion requirement' in the next section). But her overall motivational relation to the lusory goal differs from the achievement player's. Whereas the achievement player's pursuit of the lusory goal is nested in a broader, game-independent interest in maximizing 
achievement, the striving player's pursuit of the lusory goal is nested in a broader, gameindependent interest in activities like the one constituted by the very attempt to achieve the game's lusory goal.

This, then, is the sense in which the striving player engages in a game noninstrumentally: it is not that she ascribes final value to either the in-game activity or in-game achievement (like the intrinsic player), but rather that her interest in achievement within the game is motivationally grounded in a more fundamental interest in being engaged in the ingame activity constituted by the pursuit of that achievement. The pursuit of achievement thus has a role both as a means and as an end in the striving player's global motivational set. This yields a motivational feedback loop. The in-game activity can still be characterized in perfectly vanilla means-ends instrumental terms, as activity in service of winning, but the attempt to win, to achieve the lusory goal, can in turn be understood as a means to the further, game-independent end of being engaged in the in-game activity of its pursuit. In a sense then, the striving player's in-game activity, while proximally aimed at winning, is ultimately activity enacted in its own pursuit (or, if you will, for its own sake!).

Crucially, this feedback loop conception of the non-instrumental motivation that marks striving play (if 'non-instrumental' is indeed an apt term for it) differs from the noninstrumental motivation of intrinsic play. Intrinsic play requires that the in-game goods for which a player plays are final goods. No further rational grounds may be invoked to explain why an intrinsic player pursues either the in-game activity or the in-game achievement. But striving players can be intrinsic or extrinsic players. Their reasons for pursuing a particular game's in-game activity may involve valuing that activity intrinsically, but it may also be thoroughly integrated with the rest of their practical projects outside the game. As long as their interest in winning is motivationally less fundamental than their interest in the in-game activity that is the pursuit of winning, nothing prevents that latter interest from being further 
grounded in some other, more fundamental global goals (like getting fit, escaping boredom, gaining skills, etc.).

Nguyen's account of striving play thus illuminates an interesting sense of engaging in an activity 'for its own sake' - one which allows but does not require ascribing final value to the activity. Moreover, nothing in his account is inimical to the possibility of the same kind of motivational inversion or feedback loop involved in striving play occurring outside of the artificial practical context of Suitsian game play (for instance, in everyday cognitive activities picked out at a more basic level). The question that concerns us now is whether the motivational model provided by striving play could be better suited to the current aim of meeting Dickie's challenge than the model provided by intrinsic play.

Plausibly, unlike intrinsic play, striving play is not just a matter of what explains our actions with respect to the game, but also of how our in-game pursuit of the lusory goal is guided, and hence, it could serve as a model for how attention is guided in appreciation. But there is a complication: the 'submersion requirement' on Suitsian game play puts pressure on the idea that the striving player's interest in striving makes a difference to how her in-game actions are guided.

\section{THE SUBMERSION REQUIREMENT}

To be engaged in a game - to have accepted its prelusory goal and constitutive rules - is what Suits (1971: 38-41, 142-146) refers to as being in the lusory attitude. Sustaining the lusory attitude is required of achievement and striving players alike. Nguyen (forthcoming: ch. 1) offers a strong reading of what this entails: "To play a game is to behave, during the game, as if the pre-lusory goal were a final end. To be gripped by the game, to be absorbed by it, we must be able to enter the phenomenal state of holding the pre-lusory goal as a final end." 
It is not that the prelusory goal should actually figure as a final end in the player's global motivational set, but that she must temporarily induce in herself a state in which she is practically motivated by it as if it were, so that the activity that constitutes the game can emerge. Let us stick with the terminology Nguyen introduces for entering this phenomenal state-being 'submerged' in the practical perspective the game prescribes - and call this the submersion requirement on Suitsian game play.

The submersion requirement arguably imposes a greater demand on the striving player than the achievement player. When an achievement player enters a game, the prelusory goal presumably takes on and retains motivational salience for them directly and automatically, as means to the achievement goods they are after. Parsed in Nguyen's terminology: the prelusory goal automatically takes on the guise of a final end with respect to an achievement player's in-game actions. By contrast, the goods that the striving player is after attend the lusory goal's pursuit regardless of whether that pursuit succeeds. The problem is that a complete lack of interest in goods attending the lusory goal's successful achievement threatens to undermine the normative traction of the prelusory goal on the player's actions.

Nguyen (ibid.) illustrates the problem with an anecdote of a child playing Monopoly with his father and enjoying each time he wins game money so much that, whenever he approaches victory, he hands his father some of his own game money in order to extend the game. Although a parent might humour their child in this situation, there is an important sense in which they have then given up playing Monopoly. This is an instance of a more general predicament-call it the Monopoly trap - in which a player's interest in striving undermines their wholehearted pursuit of the prelusory goal.

The Monopoly trap is Nguyen's reason for construing the lusory attitude as a comprehensive submersion in the practical perspective the game prescribes. On his strong construal, submersion, for the striving player, requires completely disengaging from the 
motivational pull of her broader interest in striving, even while her ultimate reason for doing so just is to find herself engaged in striving. Notice, however, that this rules out any principled difference between how the achievement and striving players' in-game actions are guided. What differentiates them-their respective interests in achievement and striving goods - is relegated by a strong submersion requirement to figuring only in their reasons for entering and exiting the lusory attitude, and hence, to explaining their actions with respect to rather than within the game. But this would make striving play, like intrinsic play, an unsuitable model for building a Frankfurtian account of the appreciative motivational profile in terms of how attention is guided in appreciative episodes.

The crucial question, then, is whether the Monopoly trap really necessitates such a strong construal of submersion. There is reason to think that it does not. To see why, first consider achievement play. The achievement player faces no Monopoly trap, no tension between their pursuit of achievement goods and their experience of the game's prelusory goal as motivationally akin to a final end. The hazard for the achievement player is in fact the converse of the Monopoly trap; it is that their interest in achievement might undermine the normative traction not of the prelusory goal, but of the game's restrictions on permitted means. In this vicinity lies the temptation to cheat: to pursue the game's prelusory goal by flouting the game's constitutive rules.

The hazard of cheating does not, however, give us reason to construe the submersion requirement strongly, at least not as a constitutive condition on achievement play. As a matter of course, we do not expect achievement players to disengage completely from the guiding influence of their game-independent interest in achievement goods. On the contrary, the particulars of expected achievement goods typically do (and should!) make a difference to how achievement players play. When the stakes are high, skilled achievement players play to the percentages; when the stakes are low, they might opt for more risky but showy play. 
Game play does not break down until the interest in achievement puts sufficient pressure on a player's capacity to support the lusory attitude. Only such complete breakdowns of the game — when guidance by the aim to achieve renders a player's in-game actions incompatible with simultaneous guidance by the lusory goal-should be ruled out by the submersion requirement.

Much the same goes for the striving player. The Monopoly trap should not lead us to require a complete disengagement from the broader interest in striving. Striving play only breaks down when guidance by that interest defeats the motivational traction of the prelusory goal and thereby renders the player's in-game actions incompatible with simultaneous guidance by the game's lusory goal. A strong submersion requirement rules out too much. Game-independent interests in achievement or striving may make a difference to how a player's in-game pursuit of that goal unfolds, as long as this does not interfere excessively with the motivational traction that the constitutive rules and prelusory goal have on their actions.

This more moderate reading of the submersion requirement leaves us with a picture of the difference between achievement and striving play as not merely a matter of what motivates a player to take up the lusory attitude, but also of how their in-game pursuit of the lusory goal unfolds. The moderate reading thus clears the way to use striving play as analogy for building a Frankfurtian account of appreciative motivation.

\section{FROM STRIVING PLAY TO APPRECIATION}

The last two sections showed that striving play amounts to an interesting sense of game play 'for its own sake' and that, unlike intrinsic play, it finds expression in how episodes of game 
play unfold. What remains is to generalizes the motivational structure underlying striving play to how attention is guided in cognitive activities centred on objects of appreciation.

Attentional guidance can best be thought of in terms of the constraints on how cognition unfolds over time. Such constraints come in broadly two kinds (Christoff et al. 2016): automatic constraints, for instance habitual cues and mechanisms of perceptual and affective salience, that influence where our attention is directed without our executive control; and deliberate constraints, implemented by our executive functions in service of our goals. It is the presence of deliberate attentional constraints in appreciation-its involving goal-directed thought - that makes it amenable to the analogy with striving play. We can start by spelling out striving play's side of the analogy.

The crux of striving play lies in the player's complex motivational relation to the game's lusory goal. Striving players differ from achievement players with regard to the focus of the broader goals that rationalize their having and being guided by the intention to achieve the lusory goal. It is a difference, in other words, between the hierarchical goal structures within which their respective commitments to achieving the lusory goal is nested.

Goal-guided endeavours of almost any level of complexity involves some hierarchical nesting of tasks. If I am rational, the intention to have friends for dinner would typically lead to further intentions to complete tasks that I consider ways of accomplishing the goal of dinner with friends. I have to invite them, check my refrigerator, decide what to serve, go to the grocery store, etc. Commitment to each subtask counts as a move guided by the broader intention, and the subtasks figure in ways of accomplishing that intention-they are motivationally nested in the intention. Subtasks can be further divided as ways of completing them correspond to more nested intentions formed lower down the hierarchy (to invite my friends, I have to first get up off the couch to go get my phone, etc.). The initial overarching intention can also be formed under guidance of yet broader personal goals (seeing my friends 
more often, introducing two of them to each other, etc.). Goals higher up in the hierarchy serve to guide, and, in good cases, rationally justify, the tasks of achieving nested goals lower down.

This gives us a general way to characterize achievement and striving play as modes of Suitsian game play. Both kinds of players share a commitment to achieving the game's lusory goal, which in Suitsian game play is represented by a personal level mental state (an intention). Both probably have multiple broader goals higher up their motivational hierarchies served by engaging in the game, some of which perhaps guided their initial decision to play the game. The discussion of the submersion requirement in the last section showed that, in order for there to be a difference in their mode of play, they cannot differ just with respect to which goals higher up the hierarchy secure their commitment to the lusory goal; there must also be a difference in which goals higher up influence how they go about pursuing the lusory goal. Thus the striving player's in-game moves and decisions must, for some part of their pursuit of the lusory goal, be under active guidance not just of commitment to the lusory goal, but also of a goal higher up their motivational hierarchy that stands to be promoted by some in-game behaviours irrespective of their contribution to successful attainment of the game's lusory goal.

Kumiko and Siviwe are playing a friendly set of tennis after school. Both are trying to win, so they are occupied in the same Suitsian game. ${ }^{6}$ Siviwe is due to play in a tournament in a month or two, so for him the match is an opportunity to hone his craft. Unbeknownst to him, Kumiko has accepted a wager with a mutual friend, that she can win against Siviwe. In her hierarchy of goals, higher up than winning the match is the aim of winning the bet, to which the match win serves as a means. As a result, she plays in achievement mode, choosing

${ }^{6}$ To see that tennis satisfies the Suitsian analysis, start with the prelusory goal of making a tennis ball bounce twice without interruption and add materials and restrictions stepwise until you have the constitutive rules for a tennis point. 
only strategies she thinks likely to produce the win, which pushes her play towards efficiency and risk avoidance.

Siviwe also cares about the win. But his reasons for caring include the aim of improving his slice backhand before the tournament. His play is guided by that aim, and he looks for every opportunity to use his slice to good effect. This makes for riskier, less efficient play, as his topspin backhand is more secure. He loses the set, to Kumiko's delight, but Siviwe does not leave empty handed. Towards the end of the set his slice backhand starts clicking into place, and the satisfaction of hitting a few with growing confidence compensates for the disappointment of losing the match. Siviwe plays in striving mode because his ingame activity in pursuit of winning is actively guided by a goal higher up his motivational hierarchy that is satisfied by his pursuing the win in a certain way. How he plays is sensitive to features of the in-game activity he values independently of whether they are successconducive in the particular match.

At this point all the necessary materials are in hand for spelling out this paper's proposal. Here is a first gloss: appreciative engagement is the striving mode of goal-directed cognition.

In fleshing out the analogy, it should be kept in mind that the cognitive activities involved in goal-directed thought are of a different order than the practical activities of game play. Game play features explicit goals and rules, intentionally taken up by the players. In goal-directed cognition, however, cognitive goals need not always be represented by personal level mental states (see Bargh 1990) and, even when they are, they need not be within reach of consciousness to continue guiding an agent's cognition (Bos et al. 2008). We can abstract away from such differences by thinking of what Suitsian game play and goal-directed cognition have in common: both have a task-like structure, proceeding under constraints set by the agent's goals. To capture this common feature, it will be useful to have a minimal 
model of what guidance by a goal consists in. We can borrow such a model from work by Imogen Dickie (2015: 95-98). Minimally, on her model, a system realizes guidance when it includes the following components:

(A) a state of the system that represents a goal;

(B) a feedback mechanism generating reports on current status; and

(C) moves made by the system that are jointly determined by the goal at (A) and the feedback about current status at (B).

Guidance is apt when it leads to goal-fulfilment, which happens when

(D) the function described at (C) tends towards outputs that minimize the difference between the goal represented in (A) and the current status represented at $(\mathrm{B})$.

Dickie's model is fully general. It captures the basic features of guidance as it is realized across all levels of system complexity, and across both living and inanimate systems. Just as it applies to an automated heating system, so also to an agent's goal-directed actions in Suitsian game play. ${ }^{7}$

In a Suitsian game, at a broad level of description, the in-game activity consists of behaviours put out at (C) - for instance: turn shoulders!, adjust grip on racquet!, etc.-in response to intentional commitment to the game's lusory goal and its nested goals at (A) - for

7 Dickie's guidance system is similar to what Miller, Galanter \& Pribram (1960) call a 'testoperate-test-exit (TOTE) unit'. The strategy to be implemented here, of using nested iterations of such guidance systems to capture complex goal-guided behaviours, owes a debt to their seminal work in cybernetics. 
instance: I will keep the ball in play, I will foil my opponent's attempts to approach the net by placing my shots deep into the court, etc.- and perceptual feedback about the state of the game at (B)-my opponent is off balance, the ball is headed for the left sideline, etc. Behaviours at (C) are proximally determined by (A) and (B) but need not be fully determined by them.

In the striving player, another higher-order system realizes guidance relative to a goal higher up in the player's motivational hierarchy. Call the goal represented in this second system (A*) - for instance: I will practice my slice backhand. It has contents satisfied by some (A)-guided behaviours rather than others. ${ }^{8}$ Thus the feedback mechanism in the higherorder system, $\left(\mathrm{B}^{*}\right)$, will makes the overall system sensitive to features of how the (A)subsystem realizes guidance, by reporting on which behaviours are output at (C) - for instance: are there relatively many slice backhands compared to topspin ones?, how successful are they?, how does their success correlate with features of their execution?, etc. A new, complex guidance system arises in which subsequent behaviours output at (C) are jointly determined by $(\mathrm{A}),(\mathrm{B}),\left(\mathrm{A}^{*}\right)$ and $\left(\mathrm{B}^{*}\right)$. Crucially, in striving play, whether outputs at (C) render the guidance realized by the $\left(\mathrm{A}^{*}\right)$-subsystem apt is independent of whether those same outputs at (C) render the (A)-subsystem's guidance apt.

The last paragraph uses the Suitsian game of tennis to illustrate the model of noninstrumental guidance that striving play instantiates. But with the model in hand, it should be clear that it need not be specific to practical activities dependent on the lusory attitude. Generalizing to the case of goal-directed cognition is straightforward: to attend in the appreciative mode is to be engaged in perdurant cognitive activity during which attention is

8 Note that $\left(\mathrm{A}^{*}\right)$ 's satisfaction conditions will be constrained by whether the outputs of the overall complex system are compatible with guidance by $(A)$, otherwise guidance by $\left(A^{*}\right)$ would make the lower-order, (A)-guided system break down. This builds the modest submersion requirement endorsed at the end of the last section into the overall system. 
guided by commitment to a goal, and the activity constituted by that guidance is modified by second-order guidance towards manifestations we find worthwhile for reasons independent of their efficiency in attaining our first-order goal. Thus a cognitive agent engaged in appreciation has their cognition under guidance realized by a complex motivational structure including:

(A) a mental state of either personal or sub-personal level representing a cognitive goal;

(B) a feedback mechanism generating reports on progress towards the goal in (A);

(A*) a mental state representing a second-order goal that favours some (A)-guided cognitive behaviours of the agent over none, and some particular (A)-guided cognitive behaviours over others irrespective of whether they are the best available minimizers of the difference between $(\mathrm{A})$ and $(\mathrm{B})$;

$\left(B^{*}\right)$ a feedback mechanism reporting on $\left(A^{*}\right)$-relevant features of ongoing $(A)$ guided cognitive behaviours;

(C) cognitive behaviours implemented by the subject's executive functions, jointly determined by $(\mathrm{A}),(\mathrm{B}),\left(\mathrm{A}^{*}\right)$ and $\left(\mathrm{B}^{*}\right)$.

This application of the model to goal-directed cognition provides a picture of the appreciative motivational profile as involving attention guided by proximal cognitive goals that are taken up by the appreciating agent instrumentally, for the sake of cognitive activities that result from attending under the guidance of those goals. In appreciation our motivation is, in a manner of speaking, inverted: the first-order cognitive goals guiding our attention become means to the very attention they guide. We carry out cognitive tasks not primarily for the knowledge or information contingent on their completion, but to be engaged in the cognitive 
activities that constitute our attempts to complete those tasks. Crucially, this biases our strategies for completing the pertinent tasks towards attempts consisting of cognitive activities that we care (either intrinsically or instrumentally) to be engaged in.

Consider again George Dickie's Smith and Jones example from section II, in which Jones listens to remember a piece of music's details for an exam, and Smith listens with no such purpose. Dickie's claim was that they differ in their motives for attending and perhaps the degree of their attentiveness, but not with respect to the mode their attention to the music exemplifies. What does the motivational inversion model just outlined allow us to say about this case?

Recall first that intuitions about such cases are complicated by the fact that agents in ordinary circumstances are engaged in 'numerous, complex, nested, and overlapping' tasks (Mole 2012: 52), and hence, over the course of their attention to the piece, Smith and Jones may each well instantiate a mixture of appreciative and non-appreciative motivation (compare footnote 5). We can simplify by focussing only on pertinent differences between them. In as much as Jones is guided by the overarching goal of doing well on the exam, his attempts to latch onto, classify, memorize, compare, and assess features of the music will tend to emerge from and unfold in service of that overarching goal. This does not mean that his exam-focussed listening is a case of inattention or distraction from the music; on the contrary, the cognitive tasks Jones engages in will pertain directly to features of the piece and, if he cares about the exam, we should expect his listening to be attentive to a high degree. But nor does it mean that he is attending to the music in just the same way as Smith. Jones's aim of doing well in the exam makes the payoff of his cognitive efforts contingent on the efficient selection and attainment of his proximal cognitive goals. He gets what he wants when he gleans information he deems exam-relevant, irrespective of how he gleans it, and he will likely avoid expending cognitive resources on features of the music that fall outside 
exam-relevant range, or on inefficient ways of gleaning exam-relevant information. Jones attends like Kumiko plays in the tennis example: in achievement mode.

Smith's attention, on the other hand, is meant to qualify as appreciative on the aesthetic attitude theorists' criterion because, unlike Jones, he has 'no ulterior motive' for listening. We have seen, however, that this kind of contrastive gloss on appreciative motivation provides little actual purchase on what the mode of Smith's attention to the music consists in. Here the motivational inversion account steps into the gap. If Smith really is engaging with the piece in the appreciative mode, the account suggests that it must be in virtue of some ongoing, goal-directed cognitive activities pertaining to the piece, guided by an overarching secondorder interest of a different sort than that of Jones.

Let us for a moment imagine that the piece was a favourite of Smith's late grandmother and, as he hears it now, it activates in him the tacitly held goal to commemorate her. Inadvertently he finds himself actively trying to latch onto, classify, memorize, compare and assess subtle features of the piece. Many of the cognitive tasks that Smith takes up overlap with those of Jones: determining how the composer achieves certain effects, picking out the number of time signature changes in one part, anticipating the recurrence of a musical theme, and so on. But unlike for Jones, the payoff of Smith's cognitive efforts does not lie in his success at memorizing, predicting, or finding things out about the piece. Instead, Smith gets what he wants when his attempts to do so transpire in the right ways: when his listening proceeds as though through his grandmother's ears; when his anticipation of a motif foregrounds it as representative of her taste; when the manner of his focus on the rhythm in a certain passage helps call to mind the memory of her voice humming along.

Alternatively we might envision Smith's listening as guided by a less personal goalone that is in principle available to anyone who listens. Imagine, for instance, that the piece is a composition in counterpoint and Smith wishes simply to be taken in by its complexities and 
melodic interactions. As he listens, he tries, perhaps deliberately, or perhaps he simply finds himself trying, to track the individual melodic lines. Again his cognitive efforts overlap substantially with those of Jones, who might also be tracking the individual lines, say, to find out (for exam purposes) how a recurring motif is adapted in each voice. But again, the payoff of Smith's efforts do not lie in successfully keeping track of the different voices or rightly identifying variations in a recurring motif. In fact, it is sometimes the manner of Smith's failures to keep track of all the melodies simultaneously - his temporarily losing the thread of one voice as he tracks another, only for the former to reemerge delightfully a few bars laterthat gets him the payoff he is after. Smith attends, unlike Jones, in striving mode.

These examples show that it is not the specific contents of Smith's higher-order goal that matter, but rather that, whatever they are, those contents are satisfied by certain firstorder cognitive efforts irrespective of their relative efficiency or actual success. The assortment of higher-order goals that could render the mode of Smith's listening appreciative can thus vary immensely. They could be goals narrowly focussed on the particular piece, or ones that connect Smith's current listening, say, to his broader interest in the genre (as in the counterpoint example), or they could be goals not essentially tied to music or listening at all (as in the grandmother example). They could be impersonal goals that derive from formal listening practices (the counterpoint case), or they could be goals grounded in deeply subjective personal commitments (the grandmother case).

Additionally, to count as attending in the appreciative mode, Smith need not have anything that amounts to an intention to appreciate the music or, for that matter, to attend to it in the way the motivational inversion account describes. The motivational inversion account picks out a mental capacity we have and exercise independently of reflective awareness of it or ability to activate it at will. Much like our capacity to see things in the clouds or in marked surfaces precedes and provides the foundation for practices of pictorial representation (see 
Wollheim 1986: 46), so our capacity to attend to things in the appreciative mode precedes and grounds the appreciative endeavours and practices that depend upon it.

\section{CONCLUSION}

If the model developed in the last section is on the right track, then our cognitive efforts in appreciation instantiate the inverted motivation or motivational feedback loop identified in the discussion of striving play (section III). When an appreciator's cognition proceeds in pursuit of proximal cognitive goals (such as to find certain things out about the object of appreciation), those goals are ultimately pursued not for any purpose their attainment would serve, but rather for the sake of aspects of their attentive pursuit. In this narrow sense, then, appreciation does consist in attention 'for its own sake'.

The motivational inversion account meets Dickie's challenge to the aesthetic attitude theorists. It is formulated in expressly 'Frankfurtian' terms pertaining to how attention is guided over the course of appreciative episodes. Moreover, it provides a positive rather than privative analysis of the appreciative motivational profile, committing to a determinate nested structure of goals by which attention is motivated, rather than just ruling out certain kinds of motivation. But the account is admittedly unorthodox in several respects.

For a start, whereas appreciative motivation is traditionally made criterial for aesthetic mental states (such as pleasures, judgments, an attitude, or responses), it is presented here as qualifying a distinctive kind of process or activity instead. The perdurance of cognitive episodes - their unfolding over time-is not typically given explanatory import in general theorizing about appreciation. At most, it sometimes features in the claim that appreciation or aesthetic experience is 'autotelic' or 'self-sustaining' (for example in Schaeffer 2015, Dokic 2016). But on its own, the invocation of autotelicity is more notional than illuminating. One 
way to read the current account is as offering a determinate analysis of what the pertinent kind of autotelic motivation amounts to.

The account further deviates from tradition by picking out a motivational profile that is 'disinterested' or 'non-instrumental' only in an attenuated sense. It eschews any requirement that a cognitive agent must attribute final value to the activity of attending to an object of appreciation. As in the example involving Smith's grandmother in the last section, the second-order goal rationalizing and guiding an appreciator's attention may be completely integrated in an idiosyncratic set of personal ends. Token episodes of appreciation may be engaged in for entirely instrumental purposes, as long as those purposes are served by being engaged in the cognitive activity comprising the episode rather than just by the attainment of that activity's proximal cognitive goals.

Abandonment of a full-fledged, restrictive notion of disinterest is a move with some recent precedent in aesthetics. Some philosophers have, for example, been advocating for the revival of an older, Platonic tradition in which aesthetic value is considered the object proper to loving (and, hence, deeply interested) attitudes (Nehamas 2007; Riggle 2016). Others have taken issue with how the disinterest requirement erroneously casts appreciative engagement as a passive affair (Berleant 2016; Lopes 2018: 159-163). Yet another line of criticism laments that the valorization of disinterest in aesthetics has severed the arts-and our appreciative engagement with them-from the broader human activities from which they arose in the first place, and from which they derive their meaning and significance (Wolterstorff 2015).

The motivational inversion account is rooted in sympathy with these concerns, but ultimately offers a strategy for sidestepping the dispute about disinterest. On the one hand it accommodates the critics of disinterest on all fronts. It brooks no prohibition on personal concerns and passions (including loving attitudes) prompting and helping to guide an agent's 
attention in token appreciative episodes; it conceives appreciation as involving active, tasklike exercises of cognitive agency; and it integrates appreciative motivation with the broader motives underlying our practical projects outside the confines of the gallery and concert hall. Nonetheless, the account also allows the proponents of disinterest to maintain that appreciative episodes are non-instrumentally motivated in the substantive (if non-traditional) sense captured by the motivational inversion model. Live questions thus remain about the extent to which the model is compatible with, or even fitted to, the theories of some proponents of disinterest such as Schopenhauer and Bullough.

Finally, as conceived in this paper, the appreciative mode of attention is ubiquitous. The psychological kind picked out by the proposed account can be instantiated in attention to any manner of item or task, ranging from things of great aesthetic significance to the utterly mundane or frivolous. This forestalls the temptation to draw an essential connection, as the aesthetic attitude theorists did, between appreciative motivation and the aesthetic. But this is as it should be. The aim of an account of appreciative attention should be to explain why the values of things - both aesthetic and otherwise-come to fruition in experience when we attend to them appreciatively. ${ }^{9}$

${ }^{9}$ My thanks for very helpful comments on (in some cases multiple) earlier drafts of this paper to Anthony Cross, Sina Fazelpour, Alex King, Dominic Lopes, Irene Martínez Marín, Chris Mole, Thi Nguyen, Sophia Sideris, and the audience at Camp Aesthetics 2018 at UVU Capitol Reef Field Station. Thanks also for invaluable discussion of some of the main ideas to Aleksey Balotskiy, Jasper Heaton, and audiences at Uppsala University's Higher Seminar in Aesthetics, the 2018 BSA Conference at St Anne's College, Oxford, and UBC Philosophy's graduate colloquium. 


\section{REFERENCES}

Bargh, J. A. (1990) 'Goal $\neq$ Intent: Goal-Directed Thought and Behavior Are Often Unintentional', Psychological Inquiry, 1/3: 248-77.

Berleant, A. (2016) Re-thinking Aesthetics. New York: Routledge.

Bos, M. W., Dijksterhuis, A and Van Baaren, R. B. (2008) 'On the goal-dependency of unconscious thought', Journal of Experimental Social Psychology, 44/4: 1114-20.

Bullough, E. 1912. "Psychical Distance" as a Factor in Art and an Aesthetic Principle', British Journal of Psychology, 5: 87-117.

Christoff, K., Irving, Z. C., Fox, K. C. R., Spreng, R. N. and Andrews-Hanna, J. R. (2016) 'Mind-wandering as spontaneous thought: a dynamic framework', Neuroscience, 17: 718-31.

Davidson, D. (1963) 'Actions, reasons, and causes', Journal of Philosophy, 60/23: 685-700.

Dickie, G. (1964) 'The Myth of the Aesthetic Attitude', American Philosophical Quarterly, 1/1: 56-65.

Dickie, I. (2015) Fixing Reference. Oxford: OUP.

Dokic, J. (2016) 'Aesthetic Experience as a Metacognitive Feeling? A Dual-Aspect View', Proceedings of the Aristotelean Society, 116/1: 69-88.

Frankfurt, H. (1978) 'The problem of action', American Philosophical Quarterly, 15/2: 15762.

Irving, Z. C. (2016) "Mind-wandering is unguided attention: accounting for the "purposeful" wanderer', Philosophical Studies, 173: 547-71.

Iseminger, G. (2005) 'The Aesthetic State of Mind', in M. Kieran (ed.) Contemporary Debates in Aesthetics and the Philosophy of Art, 98-112. Oxford: Blackwell.

Kagan, S. (1998) 'Rethinking Intrinsic Value', Journal of Ethics, 2: 277-97.

Kant, I. (1790/2000). Critique of the Power of Judgement. Trans. P. Guyer and E. Matthews. New York: Cambridge University Press.

Kemp, G. (1999) 'The Aesthetic Attitude', British Journal of Aesthetics, 39/4: 392-99.

Korsgaard, C. (1983) 'Two Distinctions in Goodness', Philosophical Review, 92: 169-95.

Levinson, J. (2016) 'Toward an Adequate Conception of Aesthetic Experience' in Aesthetic Pursuits: Essays in Philosophy of Art, 28-31. Oxford: OUP.

Lind, R. W. (1980) 'Attention and the Aesthetic Object', Journal of Aesthetics and Art Criticism, 39/2: 131-42.

Lopes, D. M. (2018) Being for Beauty: Aesthetic Agency and Value. Oxford: OUP.

Matthen, M. (2017) 'The Pleasures of Art', Australasian Philosophical Review, 1/1: 6-28.

Matthen, M. (2018) 'New Prospects for Aesthetic Hedonism', in J. A. McMahon (ed.) Social Aesthetics and Moral Judgment: Pleasure, Reflection and Accountability, 13-33. New York: Routledge.

Miller, G. A., Galanter, E. and Pribram, K. H. (1960) Plans and the Structure of Behavior. New York: Holt, Rinehart and Winston. 
Mole, C. (2011) Attention is Cognitive Unison. An essay in cognitive psychology. Oxford: OUP.

Nanay, B. (2016) Aesthetics as Philosophy of Perception. Oxford: OUP.

Nehamas, A. (2007). Only a Promise of Happiness: The Place of Beauty in a World of Art. Princeton: Princeton University Press.

Nguyen, C. T. (Forthcoming). Games: Agency as Art. OUP.

Riggle, N. (2016) 'On the Interest in Beauty and Disinterest', Philosopher's Imprint, 16/9: 114.

Schaeffer, J.(2015) 'Aesthetic Relationship, Cognition, and the Pleasures of Art', in P. F. Bundgaard and F. Stjernfelt (eds.) Investigations into the Phenomenology and the Ontology of the Work of Art. New York: Springer.

Schopenhauer, Arthur (1819/2010) The World as Will and Representation, Vol. 1. Trans. J. Norman and A. Welchman. New York: Cambridge University Press.

Setiya, K. (2003) 'Explaining Action’, Philosophical Review, 112/3: 339-393.

Shelley, J. (2017) 'The Concept of the Aesthetic', in E. N. Zalta (ed.) The Stanford Encyclopedia of Philosophy, Winter 2017 edn. (First version published in Fall 2009 edn.) <https://plato.stanford.edu/archives/win2017/entries/aesthetic-concept/>

Stecker, R. (2006) 'Aesthetic Experience and Aesthetic Value', Philosophy Compass, 1/1: 110.

Stolnitz, J. (1960) Aesthetics and Philosophy of Art Criticism. New York: Houghton Mifflin.

Suits, B. (1978) The Grasshopper: Games, Life, and Utopia. Toronto: University of Toronto Press.

Wollheim, R. (1986) 'Imagination and Pictorial Understanding', Proceedings of the Aristotelian Society, Supplementary Volumes, 60/1: 45-60.

Wolterstorff, N. (2015) Art Rethought: the Social Practices of Art. Oxford: OUP.

Zangwill, Nick (1992) 'Unkantian notions of disinterest', British Journal of Aesthetics, 32/2: $149-52$.

University of British Columbia, Canada 